\title{
Mechanical and Biodegradation Behaviour of Jute/Polylactic Acid Green Composites
}

\author{
Jai Inder Preet Singh ${ }^{1}$, Sehijpal Singh ${ }^{2}$ and Vikas Dhawan ${ }^{3}$ \\ ${ }^{1}$ Research Scholar, IKG-PTU Kapurthala, Guru Nanak Dev Engineering College, Ludhiana, Punjab, India \& \\ Assistant Professor, Lovely Professional University, Phagwara, Punjab, India \\ ${ }^{2}$ Principal, Guru Nanak Dev Engineering College, Ludhiana, Punjab, India \\ ${ }^{3}$ Director Principal, CGC Landran, Greater Mohali, Punjab, India \\ E-Mail: jaiinderpreetsingh@gmail.com
}

\begin{abstract}
Global warming, diminution of fossil fuels, escalating oil price's are the major reasons which forces the researchers to develop green products for the sustainable development. In this research work, green composites have been developed with jute fibers as reinforcement and poly lactic acid as matrix material using compression moulding technique. All composites were developed with maintaining the reinforcement as $30 \%$ fiber volume fraction. The influence of curing temperature with the range of $160^{\circ} \mathrm{C}, 170^{\circ} \mathrm{C}$ and $180^{\circ} \mathrm{C}$ was investigated for various mechanical properties of developed composites and degradation behaviour of developed composites were analysed using soil burial test. Results acquired from the tests specify that the tensile and flexural strength decreases with upsurge in curing temperature. Morphology study using scanning electron microscopy is further justified the findings obtained from mechanical tests. Biodegradation study was done on the all the three different composites under the soil burial conditions for 9 months and results indicate that composites developed at $160^{\circ} \mathrm{C}$ degrade faster as compared to others. This study also gives an optimum curing temperature for the development of jute/PLA composites.

Keywords: Jute Fibers, Polylactic Acid (PLA), Curing Temperature, Mechanical Characterization, Green Composites, Soil Burial, Bio Degradation
\end{abstract}

\section{INTRODUCTION}

Glass fiber reinforced plastics (GFRPs) have not only higher strength to weight ratio, outstanding durability, corrosion resistance, but also have electromagnetic neutrality, lox axial coefficient of thermal expansion. However, sometimes, the advantages become trouble because of the waste FRP remains in the ground during rejection. In addition to that the supply of raw material in FRP leads to depletion of fossil fuels in the near future, and during the recycling of FRP, toxic gasses lead's to the increase the effect of global warming also. Considering all these issues, nowadays researchers are focusing on the development of a new type of material with good mechanical characteristics and can be biodegradable in nature [1]. Green composites are biodegradable composites consists of natural fibers which acts as reinforcing material and natural polymer which acts as matrix material. One of the important characteristics of green composites that they can be designed and tailored to meet the desired requirements [2]. The exponential growth in the bio composites is indicative of their wider application in future. Flax, hemp, jute, sisal, bamboo and kenaf are the popular reinforcement materials because of their low density with high specific strength and stiffness [3], cost effective and readily available. Lot of researchers reported the innovative work related to the use of natural fibers to improve the mechanical properties of polymer composites [4]. Dhawan et al. [5] investigated the effect of natural fillers on the mechanical characteristics of GFRPs and found coconut coir shows better mechanical properties as compared to the other fillers in glass/epoxy composites. Dhawan et al. [6] discussed novel approach for the prediction of forces during the drilling of composite laminates using artificial neural network. Jai Inder et al. [7] studied the effect of curing temperature on mechanical properties of jute fibers/epoxy based green composites and found that tensile and flexural strength are maximum when curing is done at $100^{\circ} \mathrm{C}$. Gomes [8] studied the effect of high concentration alkali treatment on mechanical properties of curaua fibers/corn starch based green composites and the results proved that the appropriate alkali treatment is the key technology for improving the mechanical properties of green composites. Later on lot many researchers have proposed various surface treatment techniques to improve the mechanical properties of polymer composites.

Goriparthi et al. [9] studied the effect of fiber surface treatments on mechanical and abrasive wear performance of polylactic acid/jute composites and results of thermogravimetric analysis showed a higher thermal stability for silane treated composites. T. Lee et al. [10] investigated the interfacial adhesion of ramie/acetylated epoxidized soybean oil based green composites and found that silane treated fibers improve the interfacial property. Jai Inder et al. [11] investigated the effect of alkali treatment on mechanical properties of jute/epoxy based green composites and found that $5 \%$ concentrated $\mathrm{NaOH}$ solution shows the best mechanical properties as compared to untreated jute/epoxy green composites. Martucci et al. [12] studied the biodegradation behaviour of gelatin and PLA. During the investigation, it has been found that $20 \%$ of weight loss upon 120 days of indoor soil burial.

This paper describes the research in which composites were developed with the use of woven jute fibers and polylactic 
acid (PLA). Mechanical properties were investigated for jute/PLA composites which were developed at $30 \%$ fiber volume fraction with curing temperature ranging from $160^{\circ} \mathrm{C}$ to $180^{\circ} \mathrm{C}$. In addition to that, this research also leads to analyses the bio-degradation of developed composites under soil burial experiments. Biodegradation behaviour of jute/PLA composites were investigated using scanning electron microscopy analysis.

\section{EXPERIMENTAL PROCEDURE}

\section{A. Materials and Processing}

The PLA used in this work was commercial grade of 3052D in the granular form and purchased from Natur Tec India Pvt Ltd. Jute fibers used in the form of woven mat and purchased from local market. Properties of PLA and jute fiber are mentioned in the table 1 [13] and 2. Jute fibers were composed of alpha cellulose $(60 \%)$, Hemicellulose $(21 \%)$, Lignin $(12 \%)$, Fats \& waxes $(0.4 \%)$, pectin $(0.2 \%)$, Proteins/Nitrogenous matter etc. $(0.80 \%)$ and Ash $(0.7 \%)$ [1]. Figure 1 and 2 shows the PLA and Jute fiber used in the study

TABLE I PROPERTIES OF PLA

\begin{tabular}{|l|c|}
\hline \multicolumn{1}{|c|}{ Properties } & Values \\
\hline Specific Gravity & 1.24 \\
\hline Crystalline Melt Temp $\left({ }^{\circ} \mathrm{C}\right)$ & $145-160$ \\
\hline Glass Transition Temp $\left({ }^{\circ} \mathrm{C}\right)$ & $55-60$ \\
\hline Tensile Yield Strength $(\mathrm{MPa})$ & 62 \\
\hline Tensile Elongation $(\%)$ & 3.5 \\
\hline Flexural Strength $(\mathrm{MPa})$ & 108 \\
\hline Flexural Modulus $(\mathrm{MPa})$ & 3600 \\
\hline
\end{tabular}

TABLE II MECHANICAL PROPERTIES OF JUTE FIBER

\begin{tabular}{|l|c|}
\hline \multicolumn{1}{|c|}{ Properties } & Values \\
\hline Density $\left(\mathrm{g} / \mathrm{cm}^{3}\right)$ & 1.3 \\
\hline Tensile strength $(\mathrm{MPa})$ & $393-773$ \\
\hline E-modulus $(\mathrm{GPa})$ & 26.5 \\
\hline Elongation $(\%)$ & $1.5-1.8$ \\
\hline
\end{tabular}

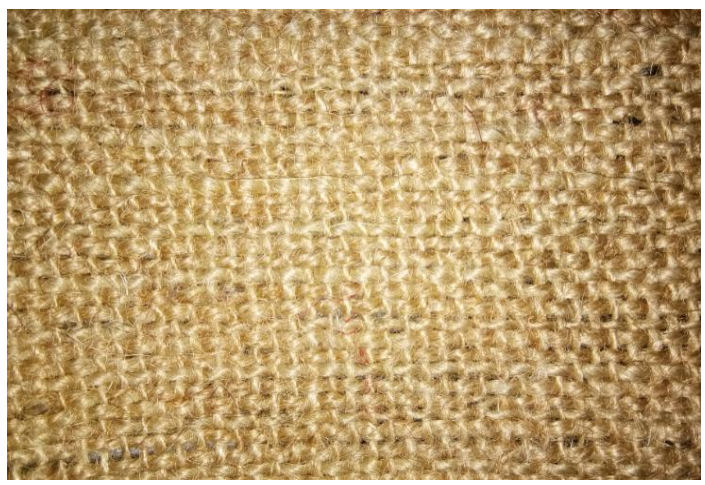

Fig. 1 Woven Jute Mat

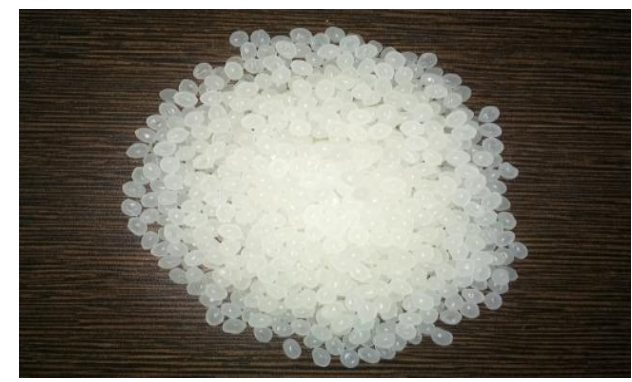

Fig. 2 Optical View of PLA in granular form

Development of the composites was done with the help of compression molding technique. The complete set up comprises of sub components as metallic upper and lower die, heaters in the form of rods, temperature sensors and a control unit to ensure the required mold temperature of the die. The dimensions of the die are selected in such a way so that developed composite should have dimensions as 320 $\mathrm{mm} \times 120 \mathrm{~mm} \times 4 \mathrm{~mm}$. In the first stage, three layers of woven jute mats were cut as per the required size of the die cavity and the calculated amount of PLA by weight were placed in the oven along with the fibers to remove the moisture content for 4 hours at $80^{\circ} \mathrm{C}$. Meanwhile, metallic die was set to heat at the specified temperature, which was further controlled by the thermocouples and control units. To avoid the sticking of PLA with metallic die, Teflon sheet was used which act as a releasing agent.

Fiber content in terms of volume has been calculated as equation $1[8]$.

$$
V_{\mathrm{f}}=1-\frac{W-W_{\mathrm{f}}}{\mathbb{P}_{\mathrm{m}} \mathrm{V}}
$$

Where $(\mathrm{Vf})=$ Fiber volume fraction, (Wf) is the fibers weight in composite, (W) is the weight of the developed composite, (V) is the volume of the developed composite and (pm) is the density of matrix material.

To calculate the fiber volume fraction, weight of the fibers were calculated with the help of weighing machine. From the initial trails it has decided to keep three layers of jute fibers, for maintaining the $4 \mathrm{~mm}$ thickness of the composite. In this study, jute/PLA composites were developed with the fiber volume fraction as $30 \%$. Firstly, tefloan sheet was placed in the cavity and on the top of that defined quantity of PLA granuals were spread over it. Distribution of PLA granuals should be uniform in the complete cavity. After that three layers of woven jute fibers were placed above the PLA layer. Again defined amount of PLA granuals were spread over the jute fibers and then cover the complete sandwitch like structure with tefloan sheet and finally closed the die with the help of an upper metallic die. The complete die which was at set temperature from the given range $\left(160^{\circ} \mathrm{C}, 170^{\circ} \mathrm{C}\right.$ and $\left.180^{\circ} \mathrm{C}\right)$ was located under the press, and $4 \mathrm{MPa}$ of pressure was applied for $4 \mathrm{~min}$, thereafter pressure was amplified to $6 \mathrm{MPa}$ for $2 \mathrm{~min}$ at constant temperature and kept the die under the load for 15 minutes curing. The composites were air cooled under the load. At $80^{\circ} \mathrm{C}$ temperature, the developed composite was 
removed out from the die and weight of laminate was recorded to get the final fiber volume fraction using equation no 1 .

All composite were developed using same procedure as mentioned above, with $30 \%$ fiber volume fraction at different curing temperature range from $\left(160^{\circ} \mathrm{C}, 170^{\circ} \mathrm{C}\right.$ and $180^{\circ} \mathrm{C}$ ). Curing temperature range was selected on the basis of trail runs and DSC test of pure PLA. The melting temperature of pure PLA was recorded as $160^{\circ} \mathrm{C}$ which was considered as the lower range and the upper range of the $180^{\circ} \mathrm{C}$ temperature was finalized based on the trials conducted and found fibers losses its strength because of burning at higher temperature of $190^{\circ} \mathrm{C}$. Figure 3 shows the procedure of developing jute/PLA composites using compression molding process.

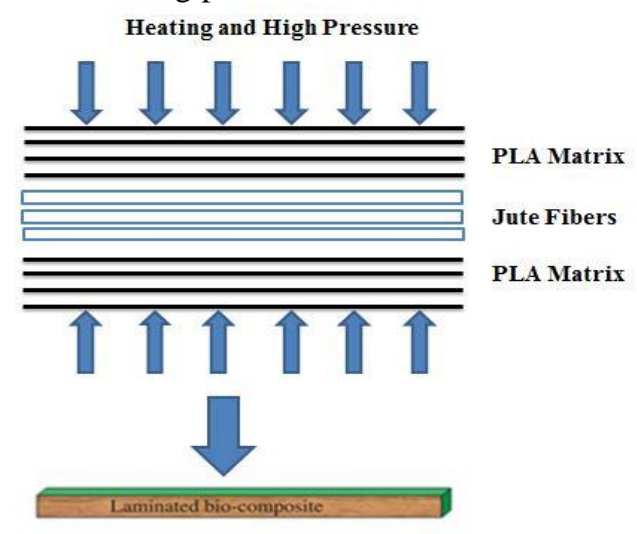

Fig. 3 Procedure for the development of green composites

Laminates were further cut as per the ASTM standards for further testing. Figure 4 shows the developed jute fiber reinforced polylactic acid composites.

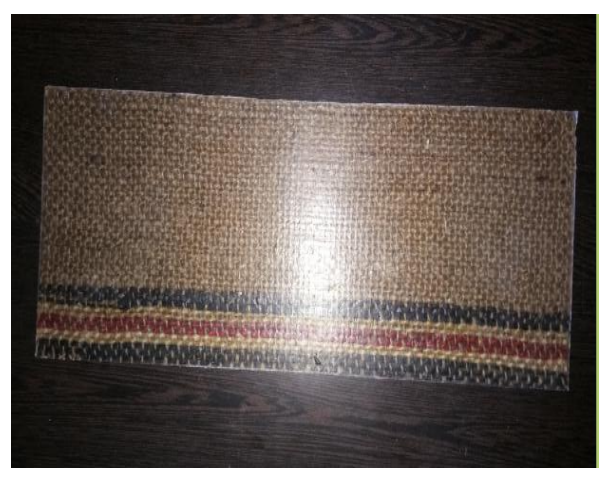

Fig. 4 Optical view of Jute/PLA composite

\section{B. Tensile Test}

The tensile test was carried on U.T.M Machine to find out the tensile strength and young's modulus as per the ASTM standards D3039 [14]. Specimen dimensions were taken as $250 \mathrm{~mm} \times 25 \mathrm{~mm} \times 4 \mathrm{~mm}$ and were cut from the developed laminate with the help of cutter. The cross speed of universal testing machine while performing the tensile test was taken as $2 \mathrm{~mm} / \mathrm{min}$. Figure $5 \mathrm{a}$,b shows the ruptured specimens of tensile and flexural test respectively.

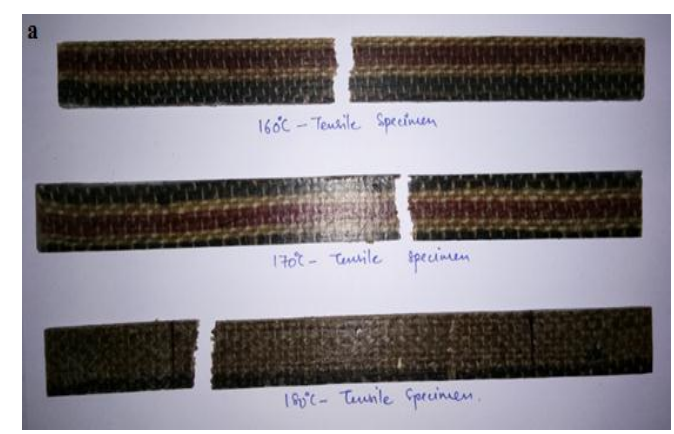

(a)

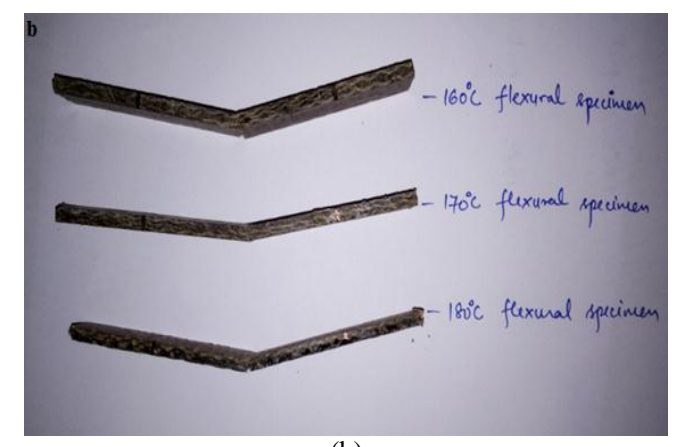

(b)

Fig. 5 Fractured tensile and flexural specimens

\section{Flexural Test}

3 point bend test was conducted on universal testing machine to find the flexural strength of developed jute/PLA composite as per ASTM standard D790-02 [15] with the specimen dimensions as $120 \mathrm{~mm}$ x $15 \mathrm{~mm}$ x $4 \mathrm{~mm}$. Flexural strength of jute/PLA composites in comparison with neat PLA material was recorded and analysed.

\section{Soil Burial Test}

The soil degradation of samples prepared at $160^{\circ} \mathrm{C}, 170^{\circ} \mathrm{C}$ and $180^{\circ} \mathrm{C}$ curing temperature with $30 \%$ fiber volume fraction was buried in a fertile soil for up to 9 months. The sample size was kept $150 \mathrm{~mm}$ x $25 \mathrm{~mm}$ x $4 \mathrm{~mm}$. The samples were removed after every 5 th week till the 40th week. The recovered samples were cleaned and dried in vacuum oven before analyze the degradation in terms of weight calculation. Percentage of weight loss has been calculated using equation 2 .

$$
\% \mathrm{WL}=\frac{W_{t}-W_{0}}{W_{0}} X 100
$$

Where Wo and Wt were the initial and final weight after dried.

\section{E. Scanning Electron Microscopy}

Morphological analysis was used to analyze the interfacial adhesion between the PLA and jute fibers and also to understand the failure mechanism of composite under the tensile load. The degradation behaviour of soil buried samples was also analysed using scanning electron microscopy. 


\section{RESULTS AND DISCUSSION}

\section{A. Mechanical Characterization of the Composites}

\section{Tensile Strength}

Test results of tensile strength and youngs modulus for jute/PLA based composites are shown in figure 6 and 7 . Results of tensile strength show that a maximum of 64.133 $\mathrm{MPa}$ was recorded at $160^{\circ} \mathrm{C}$. It has also observed that with an increase in the temperature, tensile strength decreases. The decrease in the tensile strength at higher temperature is, because of fiber burn out.

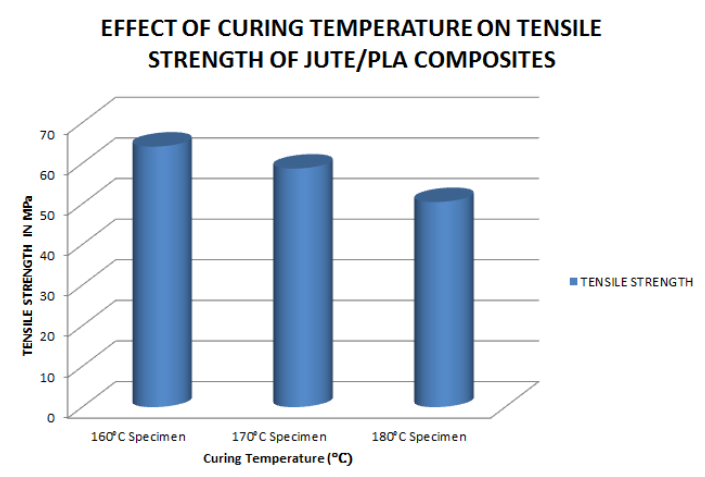

Fig. 6 Tensile strength of Jute/PLA composites

Figure 7 shows the influence of curing temperature on young's modulus of jute/PLA composites. It was observed that with increase in curing temperature, young's modulus decrease. Maximum value of young's modulus recorded as $3.393 \mathrm{GPa} 30 \%$ fiber volume fraction at $160^{\circ} \mathrm{C}$ as compared to other temperature ranges.
EFFECT OF CURING TEMPERATURE ON YOUNG'S MODULUS OF JUTE/PLA COMPOSITES

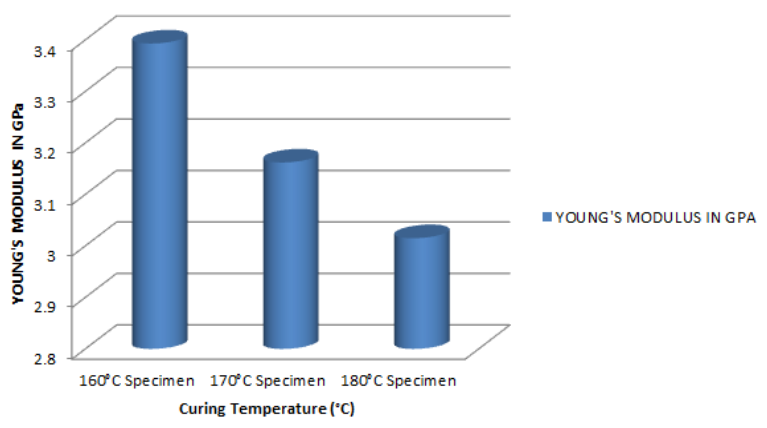

Fig. 7 Young's Modulus of jute/PLA composites

Figure $8 \mathrm{a}, \mathrm{b}$ and $8 \mathrm{c}$, shows the SEM micrographs of fractured tensile specimens of composite with $30 \%$ fiber volume fraction developed at $160^{\circ} \mathrm{C}, 170^{\circ} \mathrm{C}$ and $180^{\circ} \mathrm{C}$ curing temperature. From the figure, brittle failure of tensile specimens recorded, as some cracks were developed in the matrix. Figure 8a, b and c clearly show the comparison of interfacial bonding between fiber and matrix developed at different curing temperature. Poor interfacial bonding has been observed for the composites developed at $180^{\circ} \mathrm{C}$ curing temperature. The major reason is because of thermal degradation of fibers at the higher temperature.

Tensile strength of jute/PLA composites developed at $180^{\circ} \mathrm{C}$ was recorded as $50.495 \mathrm{MPa}$. From the SEM micrographs it was also observed that fibers were completely pulled out from the matrix during the tensile load. Fiber pull out was observed because of poor interfacial bonding between the fiber and the matrix.
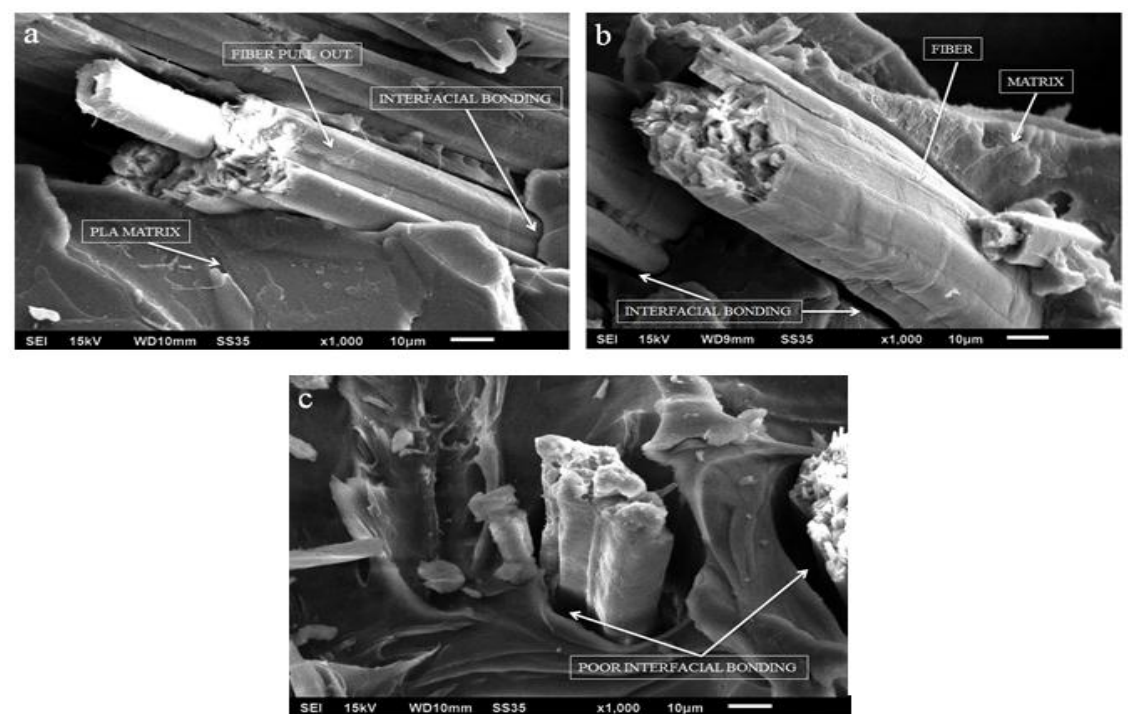

Fig. 8 SEM Images of tensile fractured specimens developed at $160^{\circ} \mathrm{C}, 170^{\circ} \mathrm{C}$ and $180^{\circ} \mathrm{C}$ curing temperature

\section{Flexural Strength}

Figure 9 shows the variation of flexural strength of developed composites at different curing temperatures. Results revel that flexural strength decreases with increase in curing temperature. Maximum flexural strength of 97.741 MPa was recorded at $160^{\circ} \mathrm{C}$ curing temperature and minimum flexural strength of $82.724 \mathrm{MPa}$ at $180^{\circ} \mathrm{C}$. Fiber burn out and fiber pull out are the main parameters effecting the flexural strength of jute/PLA composites. 
Figure 10 shows the flexural modulus of jute/PLA composites. Maximum flexural modulus was recorded as $8.694 \mathrm{GPa}$ at $30 \%$ fiber volume fraction and at $160^{\circ} \mathrm{C}$ curing temperature. Similar type of trend of flexural modulus and strength has been reported by other researcher also. The flexural strength is mainly depends upon percentage of reinforcement [6], type of surface treatment of fibers [2] and processing techniques used to develop these green composites.

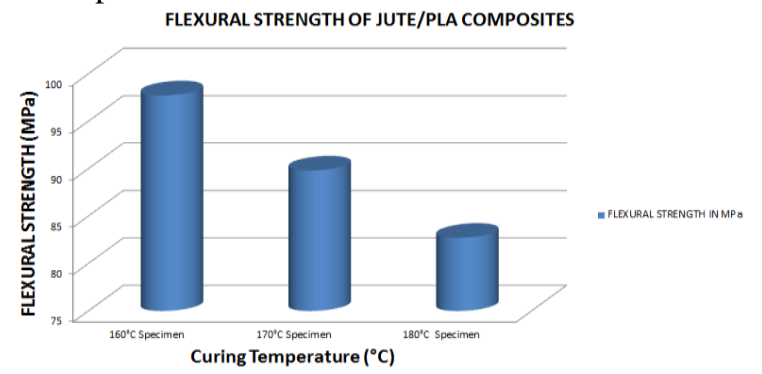

Fig. 9 Effect of curing temperature on the flexural strength of Jute/PLA composite

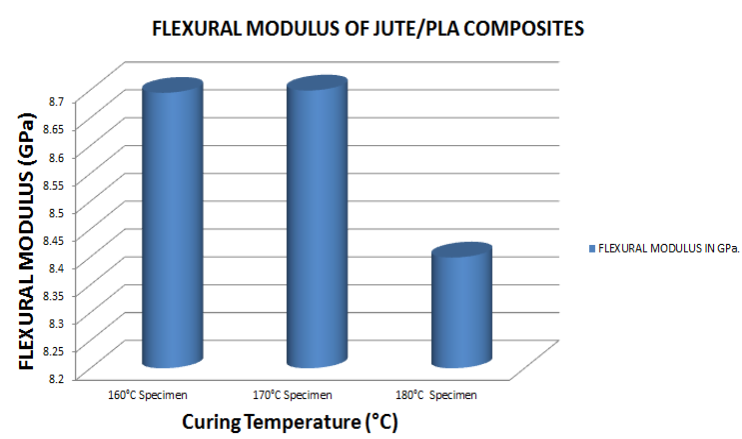

Fig. 10 Effect of curing temperature on flexural modulus of Jute/PLA composite

\section{Soil Burial}

Weight loss of specimens exposed to soil environment was considered as the indicator of degradation. Figure 11 shows the percentage degradation of jute/PLA composites developed with $30 \%$ fiber volume fraction with three temperature ranges. Selection of $30 \%$ fiber volume fraction was based on the composite showed maximum mechanical properties among other composites. The degradation period of the composites was accompanied by macroscopic changes of their physical appearance, as revealed by visual inspection and also shown in the figure 11 .

Figure $12 \mathrm{a}, \mathrm{b}, \mathrm{c}, \mathrm{d}$, e and $\mathrm{f}$ are the images of the physical appearance of the composites after degradation at 5th , 15th, 20th, 30th, 35th and 42th week of their incubation period. At the beginning of the incubation period, moisture was absorbed by all the specimens and during the 5th week of period, small cavities were developed in jute/PLA composites which were developed at $160^{\circ} \mathrm{C}, 170^{\circ} \mathrm{C}$ and $180^{\circ} \mathrm{C}$. First crack was initiated and observed during the 5 th week of incubation period. At the 15th week of degradation, maximum of $12 \%$ reduction in weight was observed in jute/PLA composites developed at $160^{\circ} \mathrm{C}$ curing temperature.

It was observed that the rate of degradation of composite developed at $160^{\circ} \mathrm{C}$ was increased drastically and at 42th week, $36 \%$ reduction in the weight was observed.

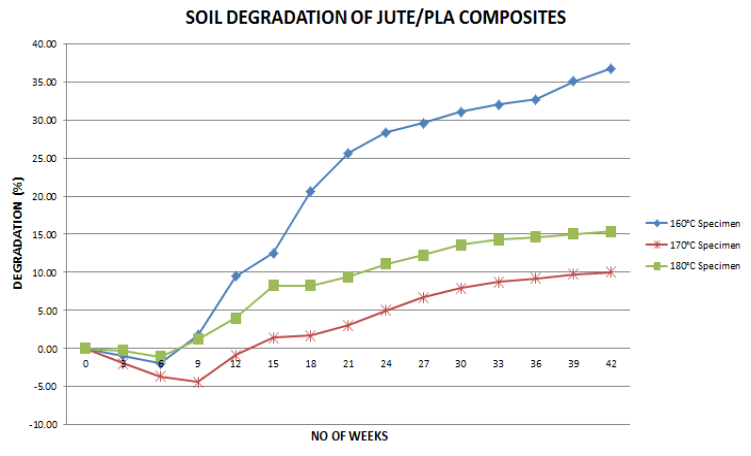

Fig. 11 Degradation of Jute/PLA composites

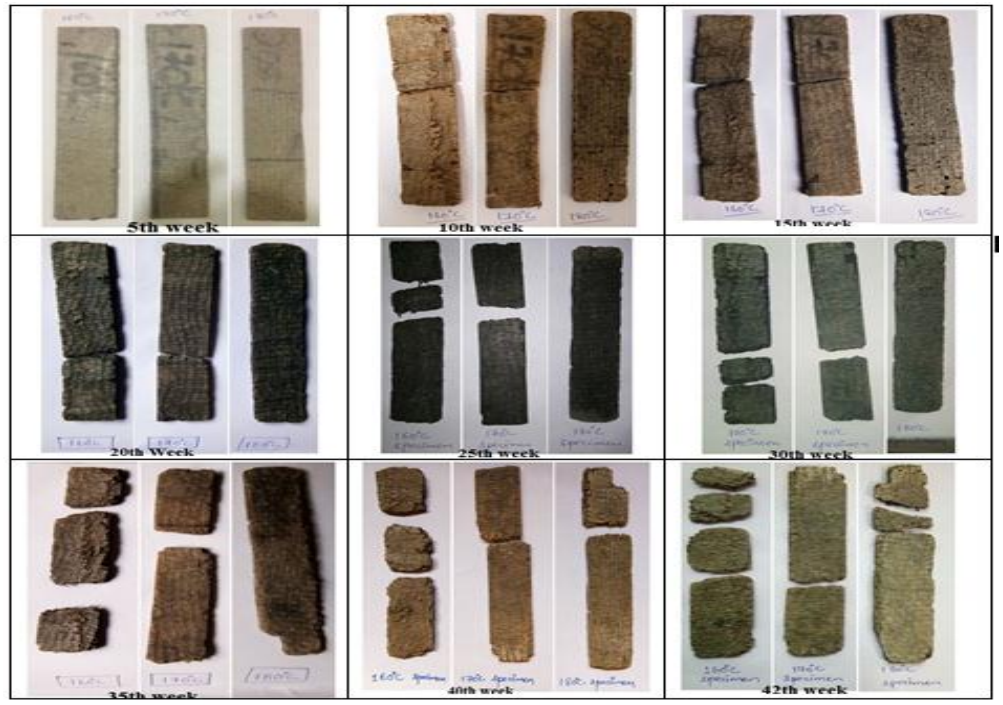

Fig. 12 Physical representation of degradation of jute/PLA composites in soil 
Figure 13 shows the SEM images of degraded sample developed at $160^{\circ} \mathrm{C}$ curing temperature. It has been observed that small holes were generated in the matrix material and fibers were degraded first as compare to matrix.

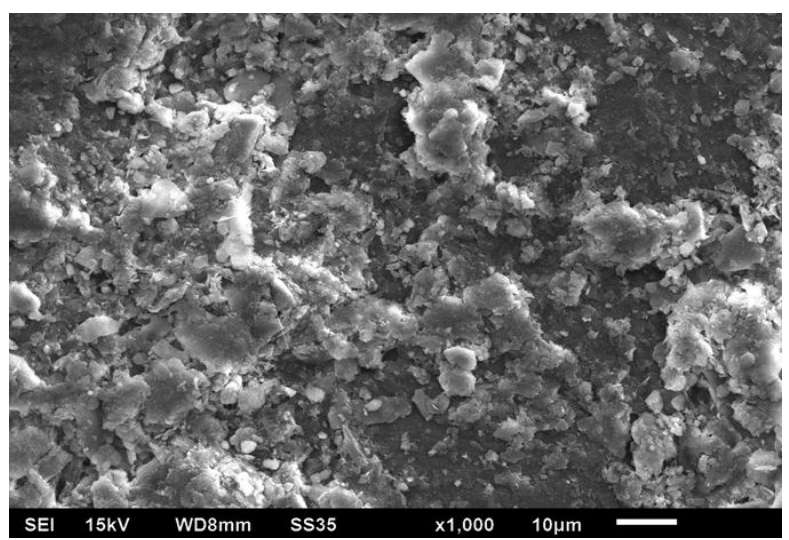

Fig. 13 SEM Images of degraded surfaces of jute/PLA composite

\section{CONCLUSION}

The following conclusions have been drawn from this research

1. The result shows that mechanical properties were improved with incorporation of jute fiber as reinforcement in the PLA matrix.

2. Testing results show that with an upsurge in the curing temperature from $160^{\circ} \mathrm{C}$ to $180^{\circ} \mathrm{C}$, tensile and flexural strength decreases. The highest value of tensile strength as $64.133 \mathrm{MPa}$ was calculated at a $160^{\circ} \mathrm{C}$ curing temperature and a minimum of $50.495 \mathrm{MPa}$ was recorded at $180^{\circ} \mathrm{C}$. Decrease in tensile and flexural strength, is mainly due to the fiber burn out at higher temperatures which leads to the more fiber pull.

3. Maximum flexural strength of $97.741 \mathrm{MPa}$ was obtained for jute/PLA composite developed at $160^{\circ} \mathrm{C}$ curing temperature.

4. Scanning electron microscopy of samples shows the brittle failure of jute/PLA composites and interfacial bonding between fiber and matrix decreases with upsurge in curing temperature from $160^{\circ} \mathrm{C}$ to $180^{\circ} \mathrm{C}$. Decrease in the interfacial bonding may be because of thermal degradation of fibers at higher temperature.

5. The soil burial test show that the degradation of jute/PLA composite caused $36.72 \%$ weight loss after 42 weeks of soil burial.
6. It clearly signifies that green composites are the future materials for industry and are eco-friendly in nature.

\section{REFERENCES}

[1] P. K. Bajpai, I. Singh and J. Madaan, "Development and characterization of PLA-based green composites: A review", $J$. Thermoplast. Compos. Mater., Vol. 27, No. 1, pp. 52-81, Mar. 2012.

[2] J. I. P. S. S. Singh, V. Dhawan, "Development and characterization of green composites: A Review", ELK Asia Pacific Journals, 2015.

[3] P. K. Bajpai, I. Singh and J. Madaan, "Comparative studies of mechanical and morphological properties of polylactic acid and polypropylene based natural fiber composites", J. Reinf. Plast. Compos., Vol. 31, No. 24, pp. 1712-1724, Oct. 2012.

[4] A. S. Pannu, S. Singh and V. Dhawan, "A Review Paper on Biodegradable Composites Made from Banana Fibers", Asian J. Eng. Appl. Technol., Vol. 7, No. 2, pp. 7-15, 2018.

[5] V. Dhawan, S. Singh and I. Singh, "Effect of Natural Fillers on Mechanical Properties of GFRP Composites", J. Compos., Vol. 2013, pp. 1-8, 2013.

[6] V. Dhawan, K. Debnath, I. Singh and S. Singh, "Prediction of Forces during Drilling of Composite Laminates Using Artificial Neural Network: A New Approach", FME Trans. J., Vol. 44, No. 1, pp. 3642, 2016.

[7] S. Jai Inder Preet Singh and V. Dhawan, "Effect of Curing Temperature on Mechanical Properties of Natural Fiber Reinforced Polymer Composites Effect of Curing Temperature on Mechanical Properties of Natural Fiber Reinforced Polymer Composites", J. Nat. Fibers, Vol. 15, No. 5, pp. 687-696, 2018.

[8] A. Gomes, "Development and effect of alkali treatment on tensile properties of curaua fiber green composites", Compos. Part A Appl. Sci. Manuf., Vol. 38, pp. 1811-1820, 2007.

[9] B. K. Goriparthi, K. N. S. Suman and N. Mohan Rao, "Effect of fiber surface treatments on mechanical and abrasive wear performance of polylactide/jute composites", Compos. Part A Appl. Sci. Manuf., Vol. 43, No. 10, pp. 1800-1808, Oct. 2012.

[10] T. S. Lee, H. Y. Choi, H. N. Choi, K.-Y. Lee, S.-H. Kim, S. G. Lee and D. K. Yong, "Effect of surface treatment of ramie fiber on the interfacial adhesion of ramie/acetylated epoxidized soybean oil (AESO) green composite", J. Adhes. Sci. Technol., Vol. 27, No. 12, pp. 1335-1347, 2013.

[11] J. Inder, P. Singh, V. Dhawan, S. Singh and K. Jangid, "Study of Effect of Surface Treatment on Mechanical Properties of Natural Fiber Reinforced Composites", Mater. Today Proc., Vol. 4, No. 2, pp. 2793-2799, 2017.

[12] J. F. Martucci and R. A. Ruseckaite, "Biodegradation behavior of three-layer sheets based on gelatin and poly (lactic acid) buried under indoor soil conditions", Polym. Degrad. Stab., Vol. 116, pp. 36-44, 2015.

[13] P. Information and P. Details, "Ingeo TM Biopolymer 3052D Technical Data Sheet Injection Molding Process Guide”, Vol. 001, No. 1, pp. 1-3.

[14] C. Materials, T. Modulus, C. Modulus, S. Precision, C. Axial and F. Application, "Standard Test Method for Tensile Properties of Polymer Matrix Composite Materials 1”, Vol. 1, pp. 1-13, 2013.

[15] ASTM International, "ASTM D 790 - 02 - Flexural Properties of Unreinforced and Reinforced Plastics and Electrical Insulating Materials", Vol. 14, pp. 146-154, 2002. 